\title{
Technology Education and the Search for Truth, Beauty and Love
}

\begin{abstract}
William S. Pretzer
In her Parade Magazine column, Marilyn vos Savant, identified in the Guinness Book of World Records as holder of the world's "Highest IQ," responded to a letter writer's earnest question, "Is there anything in the world not affected by technology?" Her answer: "Yes. There's truth, beauty, love and the hiccups" (vos Savant, 1996, p. 18). Leaving the hiccups for later, here I would like to suggest that technology actually embodies and actively promotes specific versions of "truth, beauty and love" (Mitcham, 1995; Chandrasekhar, 1987').

Technology education at the K-12 and post-secondary levels should be the venue for on-going conversations about the diverse, yet infinite quest for "truth, beauty and love" within the very real limits of "Spaceship Earth." No other part of our educational system so personally and explicitly connects individual values and actions with social and ecological consequences. With convincing authenticity rooted in its combination of theory and praxis, technology education could provide the critical forum for developing a much-needed 21 st-century "technological integrity." Integrity, after all, is what artists and parents as well as engineers and architects want in their progeny.

Technology is one of the premier ways in which humans impress their ideas and values, their Weltanschauung, on the world at large, both the natural and the
\end{abstract}

William S. Pretzer is Director of Educational Programs at Henry Ford Museum and Greenfield Village, Dearborn, Michigan. An earlier version of this article was the opening paper presented at the Technology Education Issues Symposium, Maui, Hawaii, in June 1996.

social worlds. Through technology, humans constantly remake the natural environment and human interactions in response to their ideas of what is "truth,

${ }^{1}$ It is worth noting here that I use the term "technology" with the all of the varied meanings that Carl Mitcham has identified: material objects, knowledge, process, and volition. Rather than identify each usage meaning, I will rely on the reader to apply the proper meaning given the word's context. It will be obvious that I have been heavily influenced by Mitcham, 1994. I only discovered S. Chandrasekhar's Truth and Beauty: Aesthetics and Motivations in Science while preparing this manuscript for publication, some five months after the original presentation. An astrophysicist and Nobel laureate, Chandrasekhar employs biographies of scientists in a series of lectures exploring the relationship between scientists' search for beauty and their conceptions of truth. 
beauty and love." In the United States, technological concerns have, in Neil Postman's words, transformed culture into a "technopoly" where we draw our frames of reference and symbols from the technological realm and spend an inordinate amount of time trying to cope with technological issues rather than employing technology to cope with human issues (Postman, 1992).

Like it or not, this situation makes it all the more important that we all become more literate in the symbolism of technology, more expansive in our perspectives on technology, and more creative as well as critical in our reflections on technology (Schuurman, 1995). This is precisely why students should be learning technology, so that they can participate in these conversations, creating and contributing their own visions of truth, beauty and love. To paraphrase what Samuel C. Florman has written regarding engineering, "although [technology] relies upon science and mathematical verities, in the end it responds to the demands of the human spirit" (Florman, 1996, p. 35; see also Chandrasekhar, 1987).

As Karen Zuga's recent review of the literature make clear, technology educators are overwhelmingly concerned with the what and how-the means of the curriculum - rather than with the rationales for having a curriculum at all, the why learn (Zuga, 1994). We need more debate on goals than criteria; less how and more why; less on skills and more on attitudes; less on techniques and more on relationships between technology and human values and goals. We need to focus more attention on ends rather than means, for in discussions of ends we will frame the necessary contexts for means.

Here, I would like to address, in suggestive rather than definitive terms, several issues that can contribute to a flourishing of technology education. First, this essay assesses currently popular rationales for technology education.

Second, it expresses the conviction that technology, like any part of a formal curriculum, should contribute not just to students' skill and knowledge but also to their capacity to develop moral perspectives and social wisdom. Third, it sketches the relevance of the contention that technology is more akin to art than it is to science and mathematics as a powerful "way of knowing." Fourth, the essay illustrates the importance of linking technology education to changes in social and economic structures. Finally, I suggest that broad social support for technology education will come only when educators see their mission as providing learners with opportunities to develop a personal sense of technological integrity.

\section{Reviewing Rationales}

Nearly all discussions of motivations for learning technology have been directed at decision-makers, not students. Most of the investigations have been about why educational administrators should require students to study 
technology, not about why students might be enthusiastic about learning technology (Technology Education Advisory Council, 1988; Savage and Sterry, 1990; Camelback Symposium, 1992). ${ }^{1}$

My reading of the literature suggests five basic categories of rationales for studying technology, each of which is, I am afraid, logically or historically flawed.

First, personal utilitarianism: kids need to learn technology to get and hold a job. How do we know this? Well, employers and the government tell us. Do they? We can all cite various studies that indicate a lack of technological capabilities among today's students, be they in high school or college. Among the most potent is, of course, What Work Requires of Schools: A SCANS Report for America 2000, U.S. Department of Labor Secretary's Commission on Achieving Necessary Skills (1991), or SCANS report (see also Boyett and Conn, 1992). Still, we should be careful of concluding that employment needs support technology education.

A recent survey of the CEOs of "Fortune 500" firms shows that "math, science, technical and computer skills" were mentioned less frequently than analytical and conceptual problem-solving skills and "higher-level proficiencies in writing and reading, along with effective individual and group communications skills.” A lack of technical competency was not even mentioned in a list of student deficiencies that included the inability to diagnose and solve problems, a lack of initiative, the inability to apply their skills to new and unfamiliar problems, and the inability to work effectively in groups (Nidds and McGerald, 1995, pp. 27-28). Much the same is reported for college graduates. Higher Education and Work Readiness, the report from the American Council on Education's Business-Higher Education Forum, concludes:

Corporate leaders agree that graduates are deficient in a number of areas, including leadership and communication skills; quantification skills, interpersonal relations, and the ability to work in teams; the understanding needed to work with a diverse work force at home and abroad; and the capacity to adapt to rapid change $(1995$, p. 3$){ }^{2}$

\footnotetext{
${ }^{1}$ I am referring here to a large, heterogenous literature produced by the International Technology Education Association, including the association's journal, The Technology Teacher. Interestingly, however, of the 82 responses given by teachers, teacher educators, supervisors and suppliers at a workshop held by the Technology for All Americans Project at the ITEA Conference in Nashville, March 28, 1995, only 6 explicitly mention competitiveness and 3 directly note employment opportunities. Much more commonly noted are generalizable thinking skills and aptitudes and a commitment to the students' moral right to access of knowledge. R. E. Satchwell (personal communication to The Technology for All Americans Project Writing Team, April 4, 1995).

${ }^{2}$ Specifically, notes one CEO: "Technological skills appear to be getting better, but I think deficiencies in composition, reading, writing, logic, and clarity of thought processes are becoming more pronounced." (p. 12).
} 
And before you object, "But our students learn these skills in technology education," I have to point out that none of these capabilities are unique to technology education, nor are they traditionally associated with technical disciplines, ${ }^{1}$ and most can be developed conveniently as part of a project-based, integrated curriculum that does not include technology (Florman, 1996, Chapter 8).

At the very least, we have to recognize that technological literacy, absent these other skills, will not necessarily increase the employability of our students. More importantly, we have to recognize that this simply has not proven to be a very powerful argument in favor of technology education. Parents and decisionmakers have not flocked to technology education, as opposed to, say, school-towork programs, in an effort to prepare the next generation for its challenges and opportunities.

Second, national utilitarianism: the nation only progresses to the extent its citizenry is prepared to contribute to and benefit from technology. In fact, relatively few individuals have materially initiated basic technological changes and history suggests that factors like cost of capital, governmental incentives for invention, and cultural support of innovativeness are greater influences on prosperity and growth than are workforce competencies (Mokyr, 1990; Rosenberg and Birdzell, 1986). This has certainly proven the case in the industrial development of nations such as Japan, Taiwan, and India, where technological elites have propelled change in the past century.

Especially in times of rapid socio-technological change (say the eras 18201860, 1890-1910, and 1980-2010 in the United States) work force skills commonly lag behind leading-edge and even "best practice" technologies. In each era, innovative educational programs have had to be introduced to assist the workers in catching up (Rosenberg, 1976, pp. 197-200; Stevens, 1995). ${ }^{2}$ The argument that technological literacy is critical to technological progress is not persuasive largely because it is not historically true.

Third, national security: it's a competitive, global marketplace; either we win or we lose. The United States is in a fierce economic war with other nations that we will win or lose depending on our technological capabilities. Actually, international economics is not a zero-sum game; technology is only one of many influential factors; and national employment is as affected by credit and

\footnotetext{
${ }^{1}$ See Florman (1994), Chapter 8, "Faults and Foibles," for a discussion of the limiting effects of an engineering perspective on the ability to work with others, communicate, and be persuasive. I am reminded of a comment made by then-Attorney General Ramsey Clark at a public address at Stanford University in 1968 or 1969 that "law school sharpens the mind by narrowing it."

${ }^{2}$ I consider these to be America's three industrial revolutions. These eras are associated with, in sequence, the growth of the public school system and technical associations; the definition of a new, discipline-based curriculum, trade schools, and secondary schools; and the current calls for educational reforms based on "constructivism," "authentic learning," "project-based, integrated curriculum" to replace the discipline-based curriculum that has dominated the twentieth century. These are the dominant educational responses to the three industrial revolutions that have shaped the modern economy and society.
} 
monetary policy as it is by international competition for certain types of jobs (Krugman, 1996).

Additionally, many companies are coming to learn that cooperation is an important element within the competitive system. Technologies and their interactions with social, ecological and economic factors as well as with other technical systems have become so complex and so interrelated that companies, industries and nations now have to cooperate on many issues. Coalitions, partnerships and collaborations all require shared assumptions and an ability to communicate, even while different agendas are pursued. A group executives of multi-national auto companies recently concluded that "To be More

Competitive, Competitors Feel They Must Cooperate" (Kurtz, 1996).

Further, in this global system, where cultures and languages separate people, technology is a potentially powerful cohesive element. Because technologies are potent systems of symbols, it is potentially an effective form of communication. People who cannot speak one another's language can-indeed, must - exchange, understand, and learn from one another's technological designs and systems. Focusing on individual and national competitiveness is not, in the long run, conducive to motivating learning or promoting achievement. Nor is competition a particularly effective frame of reference for working with people in the many countries where issues of appropriate scale, environmentally noninvasive technologies, and collaboration with indigenous cultures and technological traditions are far more pertinent than considerations of international trade.

Fourth, an enlightened populace that is technologically literate will make better technological decisions (Brennan, 1995). This, of course, rests on the presupposition that technology is somehow democratically determined and controlled. This reflects a broad and welcome faith in the democratic process but a naive understanding of the processes of technological choice. First, our experience does not show that even broadly held knowledge on the part of the electorate will provide good decisions in the political sphere (Wenk, 1989). Second, it has been issues of privilege and power, not knowledge and understanding, that explain the unwillingness of American businesses to accept even the minimal type of civic regulation of health, safety and environmental issues by that has been legislated since the 1960s and more recently dismantled. Similarly, it is control of the workplace and preservation of "management prerogatives" that underlay business rejection of the "Technology Bill of Rights" proposed by the International Association of Machinists and Aerospace Workers in 1981 (Shaiken, 1984, Chapter 8). In other words, technological knowledge itself is not enough; what is critical are the goals, values and principles to which the knowledge is put.

Fifth, technology is a pre-eminent example of applied problem-solving. Ironically, problem solving - the buzz-word rationale that may be one of the most potent in terms of persuasiveness within the educational community-may also be one of the most problematic. Permeating contemporary discussions about technology is a negativity that denies what most inventors and designers feel: the 
exhilaration of technology in action, the sheer joy of creating something that does what is supposed to do.

If the generic benefit of technology is problem solving, it sets up a perspective of life as a set of problems; it establishes a psychology that is negative rather than optimistic and potentially feeds youthful cynicism and alienation. Further, it implies that technology can solve all kinds of problemsstill we know that technology by itself cannot solve problems of war, famine, racism. Problem solving "techniques"-note the word-too often ignore the cultural, the political, the economic, the irrational. To concentrate on "problem solving" de-emphasizes the human interactions and social processes of defining wants and satisfying needs, and promotes the notion that technology directly leads to human benefits. In other words, we confuse technological progress (problem solving) with human progress (Postman 1992).

Each of these five rationales asserts a crassly economic/utilitarian motive for education and assumes that such rationales are motivating to others. Additionally, these are generally presented as external motivations and, as educators know, emphasizing external motivation diminishes the internal motivation for trying and mastering anything. At their root, these rationales are rooted in a technocratic view of the world. We need a new set of rationales that can only be built upon a different set of assumptions about how the world works.

\section{Technology and Values}

Technology educators too often posit education as a mechanical system and suggest that once the pedagogical mechanism is consistently fueled with domains of knowledge and process, the administration will turn the key, and the machine will run. Unfortunately, this engine lacks a spark. Technology

education will only gain its place on the educational agenda when its proponents make a moral commitment to human good, to love, in other words, and produce curricula that address that vision.

Here, I think the experience of informal science and technology centers is instructive. Riding the wave of public interest in the space program and environmental issues, science and technology centers sprang up in numerous metropolitan areas in the 1960s and 70s. These educational organizations focused on hands-on, participatory experiences that demonstrated scientific principles and technological processes. Technology centers were created and existing ones expanded at an exponential rate, funding was lavish, and their visitation increased dramatically.

Then an interesting thing happened. Attendance stagnated; funding became harder to find; the profession had an identity crisis, and started assessing its programs. The public, which had turned to the participatory nature of sci-tech centers after being turned off by the "Do Not Touch" signs in art and history museums, rather quickly got tired of hands-on "bells and whistles." Ultimately, the gadgets were technically elegant but sterile and unmotivating; they were unconnected to real life, real people, real challenges, real opportunities, real learning, and personal meaning. The IMAX theater, now in 3-D, a storytelling, indeed myth-making medium of awesome imagery and larger-than-life proportions, has become the sci-tech centers' biggest audience draw. 
The lesson is that you have to integrate human choices, authentic ambiguities and personal passions with technical virtuosity in order to hold onto the learner who has other options. Descartes' error, as Antonio R. Damasio has argued, was in trying to separate emotion from intellect. We should know better. We need to acknowledge that issues of self-esteem, motivation, feelings-our emotions-are part of the learning process; we recognize that without humanity and values there can be no true learning, no development of wisdom (Damasio, 1994; Goleman, 1995; Perkins, 1995, Chapter 7). Passion for "truth, beauty and love" is at the heart of this enterprise.

Caught in its own technocratic world view, the profession has failed to assert a clear and shared view of the key elements of a technological value system. The ultimate goal of education must be a more just, equal, and participatory society, not just more technically proficient individuals. The moral imperative of (technology) education is to promote the capability of people to be engaged, influential, thinking/doing beings. This means that people must be able to criticize and challenge as well as create and cope. It means that value-laden terms like "appropriate technology" and "sustainable design" must be at the heart, not the periphery, of teaching and learning. These issues are essential to a 21 st century education that contributes to "the formation of habits of judgement and the development of character, the elevation of standards, the facilitation of understanding, the development of taste and discrimination, the stimulation of curiosity and wondering, the fostering of style and a sense of beauty, the growth of a thirst for new ideas and visions of the yet unknown" (Israel Sheffler quoted in Bracey, 1996, p. 11).

A compelling ethical vision, I submit, will rest heavily on the antithesis of the language commonly used in technology education. It will offer a better balance and interplay between values and skills, artistry and instrumentality; discipline and creativity, production and contribution; competitiveness and collaboration; standardization and multiplicity; problem solving and opportunity generating; natural and human-made; tradition and innovation. An effective rationale for learning technology would illustrate how technology is a fundamental human expression of the diverse forms of our individual and collective constructions of "truth, beauty, and love" (Florman, 1976, p. 150; Chandrasekhar, 1987). ${ }^{1}$

This is not to argue that technology educators should necessarily teach a specific moral code. It is an observation that many technology educators already share an implicit set of values that they seldom explicitly recognize or reflect on and thus inadvertently pass on to their students. This value system is largely technocratic and positivistic in character. The position being advanced here is that technology education will be truly socially beneficial and valued when it is more balanced and worldly, and includes explicit discussion of technological

${ }^{1}$ Florman (1976), p. 150, eloquently argues that "to seek love, pleasure, wisdom, and beauty without having the solid roots in life which one achieves only by constructive activity, is to cast oneself adrift in the empty space of aimlessness [emphasis in the original]." I take his argument to apply to the general population as well as the professional engineers to whom the book is ostensibly directed. 
values so that students can reflect and develop their own ethical standards. What is truly critical is not what we value in technology, but what values we express through technology.

In two major books, the eminent educator Ernest L. Boyer has called for technology education so that elementary students "recognize the value and dignity of work, distinguish wants from needs, and understand the importance of becoming creative producers, informed consumers, and responsible conservers," while high school students should "develop the capacity to make responsible judgements about [technology's] use” (Boyer, 1995, p. 99; Boyer, 1981, p. 111). Stated thusly, few will dispute the goals; however, the devil, as they say, is in the details.

Thus, technology education ought to be centered on a love for human beings and "Spaceship Earth," not merely on the effort to extend human capabilities and their domination over nature. Herbert Read, the great scholar of industrial design, implores:

Only a people serving an apprenticeship to nature can be trusted with machines. Only such people will so contrive and control those machines that their products are an enhancement of biological needs, and not a denial of them (Read quoted in Sale, 1995, p. 212).

Technology education will only gain widespread public support when the profession explicitly develops particular "habits of mind," ways of thinking that consistently respect the environment, promote human welfare, support justice between peoples through, as well as in spite of, technology (McDonough, 1995). ${ }^{1}$ As the social critic Paul Goodman has suggested, "Whether or not it draws on scientific research, technology is a branch of moral philosophy, not of science" (Epigram in Postman, 1992).

\section{Technology as Art}

I think Ralph Waldo Emerson was aiming at something like this when he acknowledged that wisdom is revealed in many endeavors. In 1870, Emerson, hardly an apologist for technology, wrote:

Raphael paints wisdom; Handel sings it, Phidias carves it, Shakespeare writes it, Wren builds it, Columbus sails it, Luther preaches it, Washington arms it, Watt mechanizes it (Emerson, 1870, p. 47).

It is not surprising that Emerson's list includes the embodiment of wisdom ${ }^{2}$ - in short, the ability to judiciously apply experience and knowledge-

${ }^{1} \mathrm{McD}$ onough, Dean of the School of Architecture at the University of Virginia, proposes a set of design protocols that includes cost, performance, aesthetics, ecology, and "social justice." Using a type of "design filter," students in McDonough's "Institute of Sustainable Design" will consider a wide range of issues relating to how people create, produce and interact with material culture and mechanical systems.

${ }^{2}$ The New Shorter Oxford English Dictionary (Oxford, Eng.: Oxford University Press, 1993), s.v. "wisdom," defines wisdom as "the quality of being wise, esp. in relation to 
in the fine and practical arts as well as the more commonly recognized areas of religion and literature. Daedalus, in Greek legend the personification of the mechanical arts, was the patron of both the artists' and the craftsmen's guilds.

Nicholas Negroponte, founder of the Media Lab at the Massachusetts Institute of Technology, reports that " $[\mathrm{t}]$ he traditional kinship between mathematics and music is manifested strikingly in contemporary computer science and within the hacker community" (Negroponte, 1995, p. 222). It was commonly

acknowledged in the nineteenth century that art and technology had much in common: "In fact," wrote one nineteenth-century chronicler of engineering, "observation frequently shows, that the power of constructing poetry and machines are united in the same individual" (Howe, 1840, p. 391; Ferguson, 1992; Hindle, 1981). In other words, beauty and technology are intimately linked as expressions of human values and humane wisdom.

The point is that learning technology can be effectively promoted for the same reasons that arts education is promoted; namely that technology, like art, is a way of learning and knowing, of seeking "truth, beauty and love." Remember, arts educators succeeded where technology educators failed, in getting the arts officially included "into the pantheon of the "basic" school curriculum," the Goals 2000 legislation. In language that should be second-nature to technology educators, arts educator Scott T. Massey proposes that the arts represent a powerful form of symbolic communication, like numbers and languages; employ non-linear forms of thinking and problem-solving; and engage people in multisensory activities employing multiple intelligences. All of these rationales apply to studying technology (Massey, 1995, p. 5).

Massey goes on to argue that arts education provides generic aptitudes "centered in design, communication, and learning" (Massey, 1995, p. 6). Consider how closely this description of the artistic process parallels the technological process if only we substitute a few words: "playfully responding to stimuli through aesthetic [technical] sensibilities; transforming and organizing these responses into rich, multi-sensory inner imagery; expressing the imagery through an artistic [technological] work; and evaluating the artistic expression [social and ecological impact] throughout" (Scheinfeld and Steele, 1995, p. 23). It is no wonder Rube Goldberg-inspired activities are so popular among teachers and learners! Students can learn through the arts much of what we want them to 
learn to learn through technology, and vice versa. We would do well to consider more systematically and promote more seriously the affinities between technology and art as ways of learning. ${ }^{1}$

\section{Technology as History}

Finally, a persuasive argument for technology education can be made by acknowledging the course of historical change. This argument would have to be based on a broad sense of the history of learning technology and about the importance of history. A historical perspective will suggest why learning technology is not just different from but fundamentally unrelated to earlier arguments for learning manual or industrial arts or industrial technologies (Colelli, 1993; Foster, 1995; Barella and Wright, 1981).

This country is in the midst of its third industrial revolution. The first was mechanical and local in scope; the second was scientific and national; this one is electronic and global. Education has had a different role to play in each of those transformations.

The first industrial revolution was based on steam engines, machinery and the factory system. It relied little on science or book learning. Tinkerers, talented mechanics, practical problem-solvers, and entrepreneurial dreamers made the great contributions. Knowledge about how to do things - on the farm or in the factory-continued to come from traditional "know-how" or "on the job" learning. In 1845, well before the Morrill Act Federal Land Grant Act of 1862, the educator Horace Mann concluded that Americans were "a mechanical people" (Siracusa, 1979). This broad mechanical aptitude had everything to do with everyday experience, not formal education, and Mann's educational reforms for public schools did little to directly change the situation. However, the nearly 100 mechanics' institutes founded between 1818 and 1850 and the innumerable lyceums, libraries, and lectures aimed at mechanics, artisans, and other skilled working people did make available opportunities to link learning and producing (Stevens, 1995).

The second industrial revolution was based on knowledge of the physical world that simply did not exist fifty years earlier. Electricity, chemistry and steel production became the catalysts of change. The goal of production shifted from individual to mass consumption and the ideal production process was transformed from the batch system to flow: electricity flowed, chemical processes flowed, livestock slaughtering flowed, and the assembly line flowed. A new conception of the relationship between humans and technology was enunciated by Frederick Winslow Taylor, a relationship that trumpeted the primacy of "the system" and the system was "mass production."

conduct and the choice of means and ends; the combination of experience and knowledge with the ability to apply them judiciously." Surely this is what we mean, in general, when we talk about technological literacy.

${ }^{1}$ Directing our attention to the connections between technology and art may have important consequences for issues of gender equity, at least insofar as cultural assumptions and perceptions of art and technology can be altered. 
There was a paradoxical relationship of formal education to productivity under mass production. On the one hand, the new engines of change were increasingly operated by highly trained engineers and managers based on scientific knowledge developed in research laboratories staffed by university educated researchers. On the other hand, education became more and more peripheral to the needs of masses of industrial workers. Assembly-line jobs were designed so that "any idiot" could perform the job. A basic high school education was all that was needed. In this context, industrial arts (almost exclusively taught in grades 6-12) served as a basic introduction to materials and machinery for (almost exclusively male) students whose adult occupation might or might not directly rely on technological skills.

The third, and current, industrial revolution is based on the integrated circuit, powerful new methods and applications of information processing, and intensified environmental pressures. This revolution is based on continuous change and fundamentally new ways of thinking about productive activity: from careers in an industry to jobs in various industries; from hands-on to hands-off production; from generic to customized products; from repetitious labor to novel work tasks; from bureaucratic control to team-oriented work; from more to better as an indication of quality; from disposal to re-use or recycle as the end of the product development process; from extractive to sustainable production.

The implications for education are enormous and it is those implications that we struggle with now. What we do know is that this work and education for work are qualitatively different from what any previous generation has known:

The great majority of the new jobs require qualifications the industrial worker does not possess and is poorly equipped to acquire. They require a good deal of formal education and the ability to acquire and to apply theoretical and analytical knowledge. They require a different approach to work and a different mind-set. Above all, they require a habit of continuous learning.... At the very least [workers] have to change their basic attitudes, values, and beliefs (Drucker, 1994, p. 62). ${ }^{1}$

Technology educators, regardless of their organizational lineage, have to articulate a vision that is, in fact, divorced from the industrial arts background. The fundamental questions have to do with how different generations of Americans have met their needs for understanding technology through formal and informal means. The relationships between technology education and its industrial arts antecedents within the formal educational community are but a small part of this. Where Americans once learned technological attitudes and aptitudes from direct daily experience, they now learn from the media, informal learning centers, and on-the-job training. Technology educators will be better

${ }^{1}$ Drucker (1994). This essay, along with Postman, 1992, Carnevale, 1991, and Marshall and Tucker, 1992, should be required reading for all technology educators who are interested in both the development of employment skills and the liberating aspects of technology education. 
served by coming to grips with their unique role in this broad context rather than by examining narrow organizational or intellectual lineages.

A broader and truer sense of the history of technological knowledge beyond the realm of formal education will go far to aid our understanding of the need and role of technology education in the future (Pannabecker, 1995). This means explicitly learning from historical examples of the processes of inventing, designing, utilizing, and assessing technology. It means employing what we learn from experience and tradition in our present circumstances so that we can continue to learn.

\section{Technological Integrity}

Studs Terkel's latest book, Coming of Age, is made up of reminiscences of people who have lived through much of the 20th century. Terkel points out that technology has had much to do with the fact that so many people now live into and past their 70s. He also points out how much technology is on the minds of people reviewing their lives in this century:

It is not technology per se that the grayheads in these pages challenge, though there are a couple of Luddites in the crowd. It is the purpose toward which it has so often been put. Among the grievances aired: the promiscuous use of the machine; the loss of the personal touch; the vanishing skills of the hand; the competitive edge rather than the cooperative center; the corporate credo as all-encompassing truth; the sound bite as instant wisdom; trivia as substance; and the denigration of language (Terkel, 1995, p. xiv).

If we want the reminiscences at the end of the 21 st century to convey a different technological experience, we need to create a new, reflective (not reflexive) attitude toward technology. Vos Savant is correct in that the hiccups are an involuntary spasm in a biological system; technology is all about human values and volition.

To provide leadership and elicit commitment requires not primarily an intellectual agenda, the definition of a discipline, or a standardized curriculum, but a compelling vision of the future. To end racism and ensure civil rights, to create "The Great Society," to put a man on the moon and return him safely to earth-those movements attracted massive support because they appealed to Americans' "better angels," in Abraham Lincoln's memorable phrase. They specifically drew on the pursuit of "life, liberty and happiness" ("truth, beauty and love"?) and "America's traditions of ingenuity, resourcefulness and innovation." 1

Learning technology is essential precisely because it situates learners as participants in the process, provides them with real contexts for their actions,

\footnotetext{
${ }^{1}$ The latter phrase is drawn from the mission statement of my place of employment, which reads: "Henry Ford Museum \& Greenfield Village provides unique educational experiences based on authentic objects, stories, and lives from America's traditions of ingenuity, resourcefulness, and innovation. Our purpose is to inspire people to learn from these traditions to help shape a better future."
} 
and requires them to reflect about the process, the product and the impacts (Technology for All Americans Project, 1996). Technology education is the primary opportunity for students to systematically and developmentally engage technology as knowledge and process-acquiring concepts and reflecting on laboratory activities. They gain experience assessing the impact of technology as artifact and volition in real world contexts-experiencing first-hand their material surroundings and examining actual social and ecological results. It is the one opportunity young people have to develop technological confidence yet cautiousness, ambition tempered by humility (Postman, 1995, p. 122).

The mission facing technology educators now is to educate the first generation of the 21st century to be neither technocrats nor techno-peasants, neither technophobes nor technophiles; to neither fear technology nor to place undue faith in it; to bridge, in other words, C. P. Snow's "two cultures" (Snow, 1993). As an integrative way of thinking and acting, "technological integrity" expands the meanings of "a new basic" by concentrating on principled action rather than technical efficiency. Helpfully, it shifts the profession's reliance away from the concept of "technological literacy," which has been irretrievably adopted by the public and the U.S. Department of Education to refer specifically to educational technology, computer-based skills, and Information Age capabilities (U.S. Department of Education, 1996). Technological integrity implies the development of values and ethics as well as the mastery of concepts and skills. By fostering a sense of technological integrity, technology educators will contribute to their students' capacity to deal holistically with their natural, social, and technological environments. The 21 st century will demand no less.

\section{References}

Armstrong, Thomas. (1993). 7 Kinds of Smart: Identifying and Developing Your Many Intelligences. New York: Penguin Books.

Barella, Richard and Thomas Wright, eds. (1981). An Interpretive History of Industrial Arts: The Interrelationship of Society, Education, and Industrial Arts. Bloomington, IL: McKnight Publishing Co. for the American Council on Industrial Arts Teacher Education.

Boyer, Ernest L. (1995). The Basic School: A Community for Learning. Princeton, NJ: Carnegie Foundation for the Advancement of Learning.

Boyer, Ernest L. (1983). High School: A Report on Secondary Education in America. New York: Harper and Row.

Boyett, Joseph H. and Henry P. Conn. (1991). Workplace 2000: The Revolution Reshaping American Business. New York: Dutton.

Bracey, Gerald W. (1996). "Schools Should Not Prepare Students for Work." Rethinking Schools, 10(4), 11.

Brennan, Richard P. (1990). Levitating Trains and Kamikaze Genes: Technological Literacy for the 1990s. New York: John Wiley and Sons.

Business-Higher Education Forum, Task Force on High Performance Work and Workers. (1995). Higher Education and Work Readiness: The View from the Corporation. n.p.: Business-Higher Education Forum. 
Camelback Symposium: Critical Issues in Technology Education. (1992). Reston, VA: International Technology Education Association.

Carnevale, Anthony Patrick. (1991). America and the New Economy. San Francisco: Jossey-Bass.

Chandrasekhar, S. (1987). Truth and Beauty: Aesthetics and Motivations in Science. Chicago: University of Chicago Press.

Colelli, Leonard A. (1993). Tech Prep and Technology Education: A Positive Focus for Competitive Literacy. Reston, VA: International Technology Education Association.

Damasio, Antonio R. (1994). Descartes' Error: Emotion, Reason, and the Human Brain. New York: Avon Books.

Drucker, Peter F. (1994). "The Age of Social Transformation." The Atlantic Monthly (November 1994), 53-80.

Emerson, Ralph Waldo. (1870). Society and Solitude. Boston: Fields, Osgood, and Co.

Ferguson, Eugene S. (1992). Engineering and the Mind's Eye. Cambridge, MA: MIT Press.

Florman, Samuel C. (1976). The Existential Pleasures of Engineering. New York: St. Martin's Press.

Florman, Samuel C. (1996). The Introspective Engineer. New York: St. Martin's Press.

Foster, Patrick N. (1995). "Industrial Arts/Technology Education as a Social Study: The Original Intent?” Journal of Technology Education, 6(2), 4-18.

Gardner, Howard. (1983). Frames of Mind. New York: Basic Books.

Gardner, Howard. (1991). The Unschooled Mind: How Children Think and How Schools Should Teach. New York: Basic Books.

Goleman, Daniel. (1995). Emotional Intelligence. New York: Bantam Books.

Hindle, Brooke. (1981). Emulation and Invention. New York: New York University Press.

Howe, Henry. (1840). Memoirs of the Most Eminent American Mechanics. New York: W. F. Peckham.

Krugman, Paul. (1996). Pop Internationalism. Cambridge, MA: MIT Press.

Kurtz, Tom. (1996). "SAE Blue Ribbon Panel Debates Cooperation in Global Market." New Center News: US Auto Scene (Detroit), March 4, 1996, 5A.

Marshall, Ray and Marc Tucker. (1992). Thinking for a Living: Education and the Wealth of Nations. New York: BasicBooks.

Massey, Scott T. (1995). "The Arts as Knowing." On Common Ground (Fall 1995): 5-8.

McDonough, William. (1995). "Ecological Ethics and the Design Revolution." Paper presented before the Society for the History of Technology, Charlottesville, VA, October 21, 1995.

Mitcham, Carl. (1994). Thinking through Technology: The Path Between Engineering and Philosophy. Chicago: The University of Chicago Press.

Mokyr, Joel. (1990). The Lever of Riches: Technological Creativity and Economic Progress. New York: Oxford University Press.

Negroponte, Nicholas. (1995). Being Digital. New York: Alfred A. Knopf. 
Nidds, John A. and James McGerald. (1995). "Corporations View Public Education." The Education Digest (October 1995): 27-28.

Pannabecker, John R. (1995). "For a History of Technology Education: Contexts, Systems, and Narratives." Journal of Technology Education, 7(1), 43-56.

Perkins, David. (1992). Smart Schools: Better Thinking and Learning for Every Child. New York, The Free Press.

Postman, Neil. (1995). The End of Education: Redefining the Value of School. New York: Alfred A. Knopf.

Postman, Neil. (1992). Technopoly: The Surrender of Culture to Technology. New York: Alfred A. Knopf.

Rosenberg, Nathan. (1976). Perspectives on Technology. Cambridge: Cambridge University Press.

Rosenberg, Nathan, and L.E. Birdzell, Jr. (1986). How the West Grew Rich: The Economic Transformation of the Industrial World. New York: Basic Books.

Sale, Kirkpatrick. (1995). Rebels Against the Future: The Luddites and Their War on the Industrial Revolution: Lessons for the Computer Age. New York: Addison-Wesley.

Savage, Ernest and Leonard Sterry. (1990). A Conceptual Framework for Technology Education. Reston, VA: International Technology Education Association.

Scheinfeld, Daniel R. and Tammy M. Steele. (1995). "Expressive Education: Arts-Integrated Learning and the Role of the Artist in Transforming the Curriculum." The New Art Examiner (January 1995): 22-27.

Schuurman, Egbert. (1995). Perspectives on Technology and Culture. Sioux City, IA: Dordt College Press.

Shaiken, Harley. (1984). Work Transformed: Automation and Labor in the Computer Age. New York: Holt, Rinehart and Winston.

Siracusa, Carl. (1979). A Mechanical People: Perceptions of the Industrial Order in Massachusetts, 1815-1880. Middleton, CT: Wesleyan University Press.

Stevens, Jr, Edward W. (1995). The Grammar of the Machine: Technical Literacy and Early Industrial Expansion in the United States. New Haven: Yale University Press.

Snow, C. P. (1993). The Two Cultures and the Scientific Revolution. Cambridge, Eng.: Cambridge University Press (original, 1959).

Technology Education Advisory Council. (1988). Technology: A National Imperative. Reston, VA: International Technology Education Association.

Technology for All Americans Project. (1996). Technology for All Americans: A Rationale and Structure for the Study of Technology. Reston, VA: International Technology Education Association.

Terkel, Studs. (1995). Coming of Age: The Story of Our Century by Those Who've Lived It. New York: The New Press.

U.S. Department of Education. (1996). Getting America's Students Ready for the 21st Century: Meeting the Technology Literacy Challenge. Washington: The Author. 
U.S. Department of Labor Secretary's Commission on Achieving Necessary Skills. (1991). What Work Requires of School: A SCANS Report for America 2000. Washington, DC: Government Printing Office. vos Savant, Marilyn. (1996). “Ask Marilyn.” Parade Magazine (February 18, 1996), 18.

Wenk, Jr., Edward. (1989). Tradeoffs: Imperatives of Choice in a High-Tech World. Baltimore: The Johns Hopkins University Press.

Zuga, Karen. (1994). Implementing Technology Education: A Review and Synthesis of the Research Literature. Columbus, OH: ERIC Clearinghouse on Adult, Career, and Vocational Education. 